\title{
Teaching and learning in clinical rounds: a qualitative meta-analysis
}

\author{
Amin Beigzadeh', Nikoo Yamani ${ }^{2 *}$, Elham Sharifpoor ${ }^{3}$, Kambiz Bahaadinbeigy $^{4}$, Peyman Adibi ${ }^{5}$ \\ 'Management and Leadership in Medical Education Research Center, Kerman University of Medical Sciences, Kerman, Iran \\ 2Department of Medical Education, Medical Education Research Center, Isfahan University of Medical Sciences, Isfahan, Iran \\ ${ }^{3}$ Neurosciences Research Center, Institute of Neuropharmacology, Kerman University of Medical Sciences, Kerman, Iran \\ ${ }^{4}$ Medical Informatics Research Center, Institute for Futures Studies in Health, Kerman University of Medical Sciences, Kerman, \\ Iran \\ Integrative Functional Gastroenterology Research Center, Isfahan University of Medical Sciences, Isfahan, Iran
}

\begin{abstract}
Received: 27 April 2020
Accepted: 29 August 2020

Published online: 10 September

2020

*Corresponding author: Nikoo Yamani, Department of Medical

Education, Medical Education

Research Center, Isfahan University of Medical Sciences, Isfahan, Iran, Email: nikooyamani@gmail.com

Competing interests: None.

Funding information: The entire project was financially supported by the vice chancellor of research at Isfahan University of Medical Sciences. In addition, the National Center for Strategic Research in Medical Education (NASR) supported it financially with code number 960215
\end{abstract}

Citation: Beigzadeh A, Yamani N Sharifpoor E, Bahaadinbeigy K, Adibi $P$. Teaching and learning in clinical rounds: a qualitative meta-analysis. Journal of Emergency Practice and Trauma 2021; 7(1): 46-55. doi: 10.34172/jept.2020.32

\begin{abstract}
Objective: Literature on the obstacles of clinical rounds is dispersed and has not been well established under a unified systematic investigation. Teaching and learning in clinical rounds, where a variety of skills important for the medical profession, cannot be augmented if barriers related to main factors in the clinical environment are not identified.

Methods: A systematic review of English articles using Web of Science, PubMed, Embase, Scopus and Cochrane library were conducted. Relevant keywords and their synonyms were used for the domains "medical students/clinical teachers/barriers and clinical round". Additional studies were identified by searching reference lists of retrieved articles. All searches for English language articles were conducted within a 10-day period from 25 May to 3 June 2017. No time limit was considered for article searching. We contacted Kerman University of Medical Sciences to locate some studies due to access limitation.

In this systematic review, studies on the subject of barriers to clinical rounds from clinical teachers' and medical students' perspectives were identified. Our search strategy yielded 600 articles. After title and abstract review, 43 of these were obtained and finally 20 were included in the study. All data were abstracted from the included studies. Two authors independently screened the studies. We used inductive content analysis and categories of barriers were derived from the data. MAXQDA software version 10 was used for data analysis.

Results: A total of 20 articles were included and analyzed in depth. Content analysis yielded identification of 320 codes concerning barriers to clinical rounds in six categories classified as system-, climate-, teacher-, student-, patient-, and personnel-related factors.

Conclusion: Our investigation depicts primarily main barriers in teaching on rounds. In this regard, effective teaching in clinical rounds is not obtained unless barriers concerning the learning triad and its environment are explored and necessary actions are adopted accordingly.

Keywords: Clinical round, Barriers, Teaching, Learning
\end{abstract}

\section{Introduction}

The clinical environment can be defined as a place with the presence of medical teachers, medical students, clinical staff and patients revolving around patient care and clinical teaching as the two most important considerations. The clinical environment consists of inpatient, outpatient and community setting activities (1). Predominately, teaching in the clinical setting often takes place in the course of routine clinical care where patients and their problems lay the foundation for teaching medical students (2). It is in this setting where a spectrum of professional skills such as history taking, physical examination, professionalism and communication skills can be obtained from superb medical teachers which are needed for practicing medicine (3). These skills are implicitly or explicitly acquired from medical teachers upon patient's encounter at the bedside. Thus, teaching in the clinical setting in the format of routine clinical rounds help medical students to transmit from novices to experts by the help of medical teachers and the presence of patients.

Multiple researches on rounding practices have been undertaken to identify barriers in order to improve clinical rounds. For instance, in a study by Ramani et al in Boston University in 1998, they identified barriers to bedside 
teaching in different categories related to teacher, climate, system, and patient (4). In another study by Williams et al in 2004, they categorized bedside teaching barriers into personal-, interpersonal-, and environmental-related factors (5). In a multicenter qualitative study conducted by Gonzalo et al in the United States in 2010, barriers of rounding practices encountered by bedside teachers were identified and categorized accordingly (6). By the same token, in a systematic review by Beigzadeh et al challenges of clinical medical education in Iran were identified (7). Looking into researches on the challenges of clinical rounds reveals diverse factors affecting the quality of rounding practices. Such barrier factors raise concerns for teaching medical students in clinical rounds as if they set back the development of essential skills which are needed in the promotion of medical students to expert clinical teachers. Therefore, there is a need to systematically and comprehensively identify the individual obstacles embedded in the clinical environment concerning rounding practices. We believe that if obstacles are comprehensively identified then decisive actions can be taken in order to find practical solutions to tackle them. Thus, we undertook this systematic review to identify and generate an extensive list of individual barriers to clinical rounds from the perspective of medical teachers and medical students as the main stakeholders in the clinical setting. We postulate that the findings of this study can be a basis for more research concerning teaching in the clinical environment to manage clinical rounds more effectively. A reliable synthesis of the available evidence with pre-specified eligibility criteria in order to address our specific research question "what are the barriers of rounding practices from the perspective of medical teachers and medical students" has been conducted.

\section{Methods}

The authors of this paper declare that they have undertaken another systematic review concerning strategies for teaching in clinical rounds (8) in which the same method was adopted and the method section of both papers may have some similarities.

\section{Search methods for identification of studies}

In order to collate articles related to the objective of our investigation, we conducted a systematic search using Web of Science, PubMed, Embase, Scopus, and Cochrane library (Table 1). As our goal was to identify as many relevant studies as possible, we did not limit our searches

Table 1. Search syntax for Web of Science, PubMed, Embase, Scopus, and Cochrane library

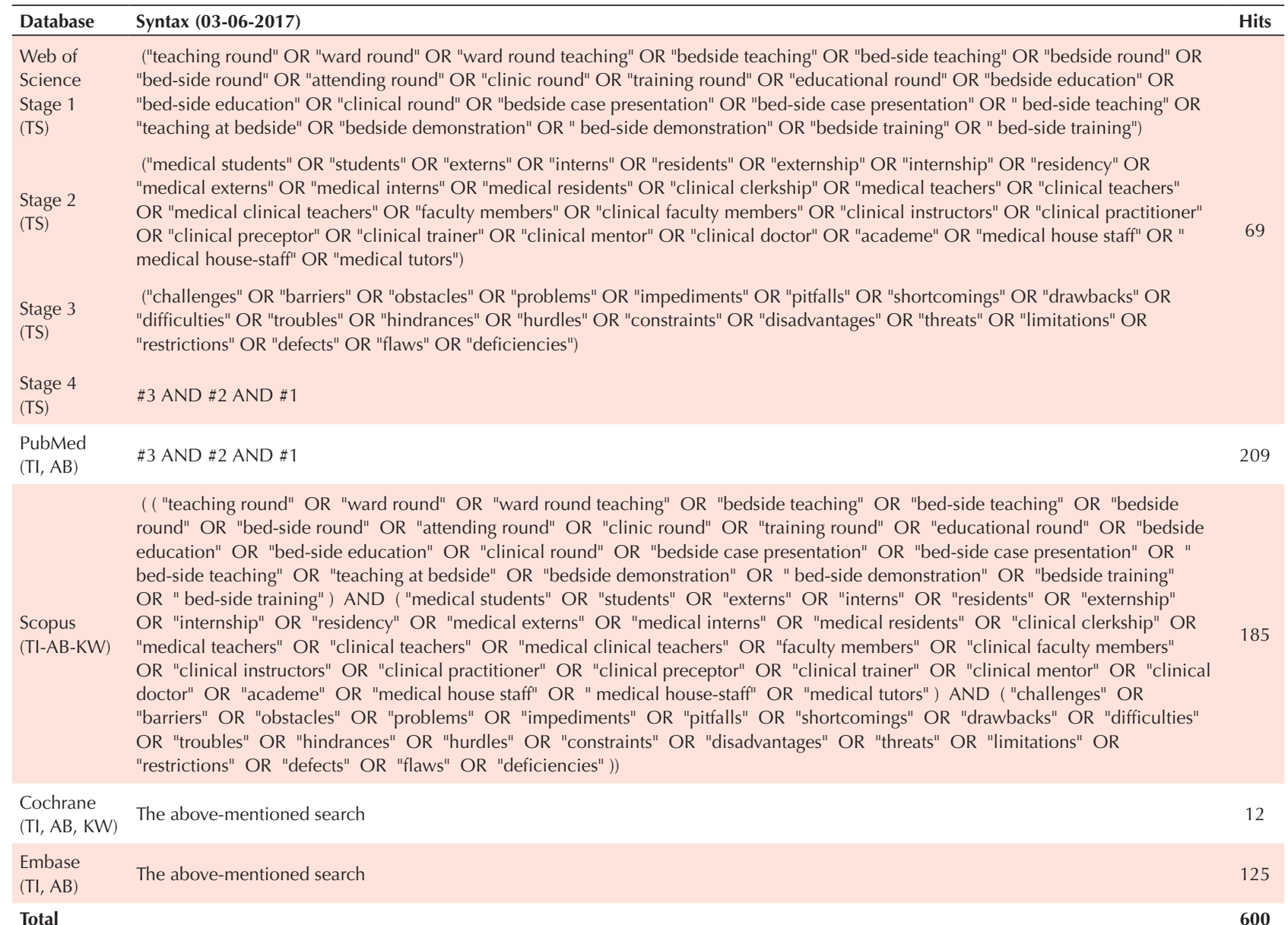


to a specific time period. Synonyms were used for the domains "medical students/clinical teachers/challenges" and the determinant "clinical round" (Table 1). As can be seen from the search syntax, comprehensiveness and relevance were taken into account when developing the search strategy. In order not to miss any potentially relevant articles, the reference sections of all retrieved articles were manually scanned (Figure 1).

\section{Criteria for considering studies for this review}

Our inclusion criteria encompassed (A) Englishlanguage articles, (B) full-text electronic articles, (C) articles regarding the barriers to clinical rounds from the perspectives/opinions of clinical teachers and medical students, (D) original articles not letter to editor, short communication, review article, editorial, commentary, conference paper, and discussion paper and (E) articles with any research design could be included in our systematic review.

\section{Screening process and selection of studies}

After aggregating all articles identified in the target databases, duplicates were removed in the preliminary screening stage. Then, based on title and abstract screening, irrelevant articles were excluded. In the second stage of screening, on account of inclusion/exclusion criteria and full text assessment, eligible studies were identified and included in our systematic review. Due to lack of access to some articles, the main medical library of Kerman University of Medical sciences was contacted to find these studies.

\section{Verification of extracted data}

Before compiling and conducting the searches, one of the authors (a healthcare librarian) with relevant expertise in searching facilitated the development of the search syntax. Another member of our research team did the searches in the target databases in order to extract or obtain data. At this stage, modifications were made to the search syntax. As reliability of our data was salient, two members of our team independently conducted the eligibility assessment of articles based on the title and abstract of retrieved articles. This was also done for full text assessment.

In terms of article inclusion, if any disagreement existed between the two reviewers, another member of our research team was contacted to resolve any discrepancies. In case of existing disagreement, we sought help from a person outside the research team. It is significant to note that reviewers were not blinded to the names of authors or journal publication when assessing the relevance of studies.

\section{Data abstraction}

In order to abstract data, a data abstraction form was developed. This form contained information concerning the objective of the study, barriers to clinical rounds implicated in the study, first author's name, type of study design (any type), participants, sample size, geographical location of the study, and year of publication. If case of not missing any important information, two members of the

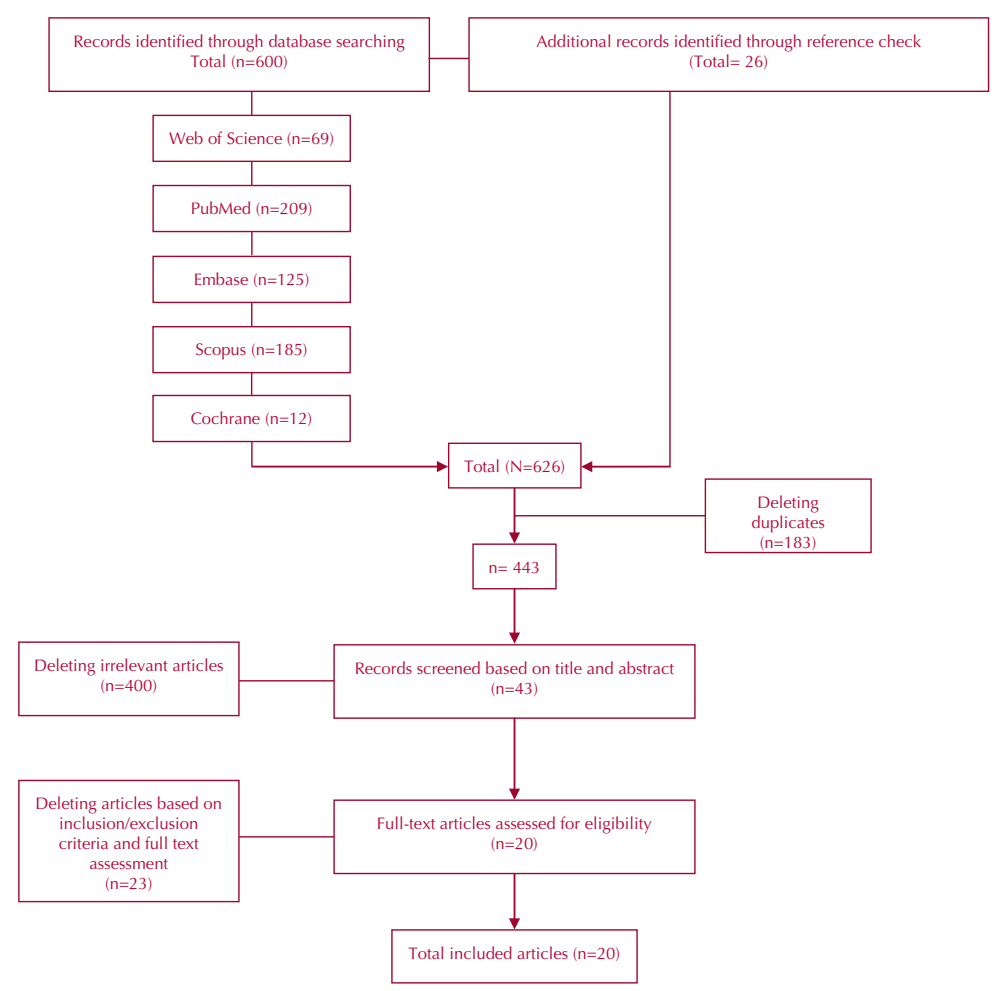

Figure 1. Flow-chart depicting the literature search and study selection process 
research team abstracted data. In this regard, a member of the research team completed the abstraction form (initial data abstraction) for each article and this was cross checked by another member of our team.

\section{Qualitative analysis of barriers to clinical rounds}

We used inductive content analysis approach to analyze data. Content analysis is a method of analyzing written, verbal or visual communication messages (9). Through this method, the researchers can test theoretical issues to enhance understanding of the data. In addition, it would be feasible to distil words into fewer content-related categories, thus words, phrases, and the like share the same meaning (10). This method involves an iterative process allowing themes and patterns to arise from the data (11).

Adopting this approach, all identified references to barriers of clinical rounds were considered as specific codes. Based on similarities and differences among the phrases or codes, subcategories were emerged from data. Finally, a category was allocated for related subcategories. The entire process was crossed checked by other members of the research team until reaching completeness and agreement on the final contents. We used the consultation of an external reviewer for coherence and consistency.

\section{Results}

\section{Study selection}

In total, based on the search strategy, we identified 600 articles (Web of science 69 hits, PubMed 209 hits, Embase
125 hits, Scopus 185 hits, Cochrane 12 hits, Reference check 26 hits). After removing duplicates, 443 articles remained. Screening continued based on title and abstract and 400 studies were discarded and 43 studies were finalized for further review. We took into consideration the inclusion/exclusion criteria as well as full text perusing and finally 20 articles had insightful information related to barriers to rounding practices and were analyzed in depth.

\section{Study characteristics}

Concerning the year of publication, one article (5\%) was published in 2016. Nine articles (45\%) were published between 2013 and 2015. Also, in each year of 2011 and 2010 , one article (5\%) was published. Four articles (20\%) were published in $2009(\mathrm{n}=2)$ and $2008(\mathrm{n}=2)$. In addition, one article (5\%), two articles (10\%) and one article (5\%) were published in 2006, 2003 and 1998, respectively.

It is also important to mention that most of the studies were conducted in USA $(n=6)$, the UK $(n=5)$, and Australia $(n=3)$. The rest of the studies were conducted in countries such as Iran $(n=1)$, Pakistan $(n=1)$, Saudi Arabia $(n=1)$, New Zealand $(n=1)$, India $(n=1)$, and Germany $(n=1)$.

In terms of data collection method, nine studies used a questionnaire $(3,12-19)$, five studies used focus group discussion (4,5,20-22), three studies used interviews $(6,23,24)$, and one study used Nominal Group Technique (NGT) (25). In addition, two studies used a combination of methods; questionnaire-group discussion $(26,27)$. Detailed information is shown in Table 2.

Table 2. Summary of included studies identifying the barriers to clinical rounds

\begin{tabular}{|c|c|c|c|c|c|}
\hline Author & $\begin{array}{c}\text { Design } \\
\text { (data collection) }\end{array}$ & Participants & Sample size & Country & Year $^{\mathrm{a}}$ \\
\hline $\mathrm{Al}$-Swailmi et al & Focus group discussion & Fourth-year and fifth-year medical students & 75 & Saudi Arabia & 2016 \\
\hline Soltani Arabshahi et al & Interview & Clinical teachers & 9 & Iran & 2015 \\
\hline Holla et al & Questionnaire & Clinical teachers, Senior residents & 94 & India & 2015 \\
\hline Jones and Rai & Questionnaire & Medical students & 368 & UK & 2015 \\
\hline Khan & $\begin{array}{l}\text { Questionnaire, Group } \\
\text { discussion }\end{array}$ & Clinical teachers & 18 & Pakistan & 2014 \\
\hline Force et al & Questionnaire & Surgical consultants, Fourth-year medical students & 35 & UK & 2014 \\
\hline Gonzali et al & Telephone interview & Attending physicians & 34 & USA & 2014 \\
\hline Indraratna et al & Questionnaire & Senior medical students & 517 & Australia & 2013 \\
\hline Shehab & Questionnaire & Specialist registrars (SPRs), Consultants & 45 & UK & 2013 \\
\hline Dybowski and Harendza & Questionnaire & Attending physicians, Consultants, Residents & 51 & Germany & 2013 \\
\hline Claridge & $\begin{array}{l}\text { Small group discussion, } \\
\text { Questionnaire }\end{array}$ & $\begin{array}{l}\text { Specialist registrars (SPRs), Foundation year } 1 \text { and } 2 \text { doctors } \\
\qquad \text { (FY1, FY2) }\end{array}$ & 47 & UK & 2011 \\
\hline Dewhurst & Focus group discussion & $\begin{array}{c}\text { Specialist registrars (SPRs), Senior house officers (SHOs), } \\
\text { Foundation year } 1 \text { doctors (FY1) }\end{array}$ & 17 & UK & 2010 \\
\hline Gonzalo et al & Questionnaire & Residents, Third-year medical students & 153 & USA & 2009 \\
\hline Jaye et al & $\begin{array}{l}\text { Group interview, Individual } \\
\text { interview }\end{array}$ & Clinical teachers, Fourth-year medical students & 21 & $\begin{array}{l}\text { New } \\
\text { Zealand }\end{array}$ & 2009 \\
\hline Williams et al & Focus group discussion & Fourth-year medical students, First and second year residents & 33 & USA & 2008 \\
\hline Castiglioni et al & NGT technique & Residents, Interns & 28 & USA & 2008 \\
\hline Celenza and Rogers & Questionnaire & Registrars, Consultants & 31 & Australia & 2006 \\
\hline Ramani et al & Focus group discussion & Chief residents (PGY4), Program directors, Bedside teachers & 22 & USA & 2003 \\
\hline Janicik et al & Group discussion, Workshop & Clinical teachers, Senior residents & 135 & USA & 2003 \\
\hline Nair et al & Questionnaire & Clinical teachers & 120 & Australia & 1998 \\
\hline
\end{tabular}

a Sorted by year of publication. 


\section{Qualitative analysis findings}

Content analysis yielded identification of barriers to clinical rounds in six major categories related to the system, climate, teacher, student, patient and personnel. Totally, 320 codes were extracted from the identified articles. The majority of codes were related to patient-related factors $(n=84)$ and the minimum number of codes were related to personnel-related factors $(n=4)$ (see Table 3$)$.

\section{Discussion}

This systematic review was designed to identify the barriers to clinical rounds from the perspective of clinical teachers and medical students. In this review, we identified 20 articles concerning the topic under investigation. On the premise of the obtained findings and by taking them into consideration as well as making efforts to tackle the obstacles relevant to each bedside encounters, the rounding practices can be improved and their effectiveness will be

Table 3. Barriers to clinical rounds identified in the English-language literature (320 total coding references)

\begin{tabular}{|c|c|c|c|}
\hline Category & Subcategory & Frequency of code ${ }^{a}$ references, no. $(\% \text { of } 320)^{b}$ & Total code frequency $(\%)$ \\
\hline \multirow{9}{*}{ System-related factors } & Poor planning & $9(2.8)$ & \multirow{9}{*}{$49(15.3)$} \\
\hline & System's monitoring flaws & $8(2.5)$ & \\
\hline & Physical environment constraint & $8(2.5)$ & \\
\hline & Inadequate workforce & $5(1.5)$ & \\
\hline & Technology-related & $5(1.5)$ & \\
\hline & system unrecognition for clinical rounds & $5(1.5)$ & \\
\hline & Lack of physical facility & $4(1.3)$ & \\
\hline & System prioritizations & $3(0.9)$ & \\
\hline & Medical record-related & $2(0.6)$ & \\
\hline \multirow{6}{*}{ Climate-related factors } & Psychological atmosphere & $17(5.3)$ & \multirow{6}{*}{$69(21.6)$} \\
\hline & Environmental-related & $15(4.7)$ & \\
\hline & Time constraint & $14(4.4)$ & \\
\hline & Crowdedness & $14(4.4)$ & \\
\hline & Poor communication & $5(1.5)$ & \\
\hline & Learning resources & $4(1.3)$ & \\
\hline \multirow{10}{*}{ Teacher-related factors } & Lacking expertise & $15(4.7)$ & \multirow{10}{*}{$69(21.6)$} \\
\hline & Lacking motivation & $11(3.4)$ & \\
\hline & Poor organization & $11(3.4)$ & \\
\hline & Poor Preparation & $9(2.8)$ & \\
\hline & Excessive responsibility & $8(2.5)$ & \\
\hline & Poor time management & $6(1.9)$ & \\
\hline & Lack of positive role models & $4(1.3)$ & \\
\hline & Low quality of teaching & $3(0.9)$ & \\
\hline & Lack of faculty development training & $1(0.3)$ & \\
\hline & Inaccessibility to teachers & $1(0.3)$ & \\
\hline \multirow{8}{*}{ Student-related factors } & Students' indiscipline & $11(3.4)$ & \multirow{8}{*}{$46(14.4)$} \\
\hline & Students' incompetency & $11(3.4)$ & \\
\hline & Lacking motivation & $8(2.5)$ & \\
\hline & High workload/fatigue & $5(1.6)$ & \\
\hline & Poor participation & $4(1.3)$ & \\
\hline & Poor preparation & $3(0.9)$ & \\
\hline & Lack of courtesy to students & $2(0.6)$ & \\
\hline & Learner autonomy & $2(0.6)$ & \\
\hline \multirow{9}{*}{ Patient-related factors } & Patient selection problems & $34(10.6)$ & \multirow{9}{*}{$83(25.9)$} \\
\hline & Concern for patient welfare & $13(4.1)$ & \\
\hline & Patient privacy infringements & $11(3.4)$ & \\
\hline & Lack of patient cooperation & $7(2.2)$ & \\
\hline & High patient volume & $6(1.9)$ & \\
\hline & Lack of courtesy to patients & $5(1.6)$ & \\
\hline & Low patient volume & $3(0.9)$ & \\
\hline & Use of medical jargon & $2(0.6)$ & \\
\hline & Language barrier & $2(0.6)$ & \\
\hline \multirow{3}{*}{ Personnel-related factors } & Low staff morale & $2(0.6)$ & \multirow{3}{*}{$4(1.2)$} \\
\hline & Disinterested staff & $1(0.3)$ & \\
\hline & Inaccessibility to staff & $1(0.3)$ & \\
\hline
\end{tabular}

a Sorted by the number of frequency from the highest to the lowest

${ }^{\mathrm{b}}$ Code references show the number of times the specific code was identified. 
augmented. Findings revealed six main categories and 45 subcategories regarding the obstacles of clinical rounds (see Table 3). Detailed information and more elaboration on the main categories are provided below.

\section{System-related factors (49 codes, 15.3\%)}

The most dominant obstacle with the highest frequency in this category was related to poor planning. Barriers such as inappropriate shift time (23), conflict between clinical round and hospital administration (20), inappropriate sharing of learners among teachers, and unsuitable allocation of educational activities in rounds (23) were some system-related factors. Besides, our literature review indicated that there are hindrances concerning monitoring related to program evaluation and feedback (23) as well as monitoring students on rounds when interacting with patients (21) which can reduce the quality maintenance within the system. It is crucially important to provide corrective feedback to medical students as it is an essential component of effective learning (22).

A very important obstacle which needs a considerable attempt to be tackled by the system is the physical environment where bedside encounters occur. Several reports have shown that the physical environment is limited and patients' rooms are too small to accommodate a large group of students at the bedside $(5,6,23)$.

If it is expected to gain a lot from a bedside encounter and cover most of the necessities regarding the clinical knowledge and skills, there is a need for sufficient human resources (i.e. teachers and ancillary staff). Thus, the clinical system should have a plan to recruit enough workforces for the hospitals. Our review reaffirms lack of such resources in clinical rounds $(19,23,25,27)$.

Another interesting finding is the effect of technology on rounding practices. As mentioned in the literature, overreliance on technology (5), overabundance of data leading to discussion of the data rather than the patient (6), and devaluation of clinical skills by technology (5), all diminish the wealth of clinical rounds opportunities to nurture medical students.

We should bear in mind that the priority of service provision and patient care to bedside teaching (24) and the priority of postgraduate education (23) are some very tremendous issues which can put teaching on rounds a second important consideration. This accentuates the necessary actions which are needed on part of the clinical system to increase the recognition of conducting rounds and consider it as a high priority in the system. We believe that the barriers identified in this category are vital aspects because if such obstacles exist in the context of teaching and learning on rounds, the resultant would be the flaws in conducting effective rounds as system plays a pivotal role in this regard.

Climate-related factors (69 codes, 21.6\%)

Teaching at the bedside is fraught with anxiety and fear around presenting patients (24), learner humiliation $(5,13,23)$, feeling of trepidation to ask questions and be corrected in front of patients $(24,28)$, unexpected questions put forward and concern to provide an answer $(21,28)$. Besides, medical students have concern with their performance in front of the patient and the attending physician (15) as well as doing clinical examination in front of peers (12). As such intense atmosphere permeates, teachers must not ask "read my mind types of questions" from learners and provide gentle corrections when needed.

The climate in which rounding practices are being done should be managed and planned. In this regard, interruptions should be minimized. By the same token, it is very important to conduct rounds in a quiet place away from patients' companions. The obstacles found in the literature mentioned instances such as interruptions by phone calls, visitors and pages $(3,4,17,18)$, excessive noise $(3,5,23,27)$ and poor ventilation of the clinical environment (23).

Another important finding is that the time required to conduct a clinical round has been mentioned as a primary hindrance to performing rounding practices $(3,13,14,17,19,20,26,27)$. It seems that when a clinical round is done correctly, it might require more time. But there seems to be other factors which make teaching on rounds too limited. We content that these can be high patient volume and turnover, and involvement in other responsibilities.

A very striking barrier can be the presence of a large crowd during a clinical encounter. This makes the job of the medical teacher more difficult, especially, when it comes to teaching students with different grades or levels. The presence of multiple students diminishes the golden time which students can use and gain mastery by examining patients, but this opportunity is evaded as little time can be devoted to each student on rounds. Literature review is replete with instances of crowdedness hindering the effectiveness of clinical rounds $(6,18,19,24,26)$.

As a major part of a treatment process for a patient is done through communication among physicians, nurses and medical students apart from history taking and physical exam to name a few, evidence highlights that effective clinical practice involves many instances where critical information must be accurately communicated (29). Our literature review indicated that lack of suitable communication among all groups in the clinical environment exists $(23,25)$. When the medical team does not communicate effectively, patient safety would be at risk and it creates situations where medical errors can occur (30). Evidence indicates that the educational environment is one of the most prominent factors in the process of teaching and learning and a positive learning environment is a major determinant for learning and can lead to increased satisfaction, achievement and success (31). 
Teacher-related factors (69 codes, $21.6 \%$ )

Our literature search highlights that the quality of teaching on rounds is not sufficient as clinical teachers have inadequate clinical knowledge and skills $(4,5,6)$, are inexperienced with bedside teaching $(4,17,19)$ as well as teaching clinical examination (20), and have poor knowledge on highlighting important physical findings or teaching points (25). We contend that when teachers spend less time with medical students observing and correcting their clinical skills or are hesitant to teach at the bedside, the resultant would be a decline in clinical expertise among students and faculty. This lack of expertise can be rectified by seeking help from senior experienced clinicians as well as participation in faculty training workshops on clinical skills.

According to the obtained data, medical teachers are not motivated or enthusiastic in teaching $(4,21,25,27)$. Effective rounds need the attention of medical teacher for the active involvement of the team in order to make rounding practices more invigorating. This finding is corroborated by other studies $(25,32)$. Teacher motivation is crucial to the success of a clinical encounter.

Another important finding of our review which can significantly devalue and affect the formation of professional skills is excessive responsibility of medical teachers. Evidence signifies that clinical or research responsibilities (4), and ambulatory or administrative responsibilities $(5,18)$ have an impact on the dedicated time to teach on bedside. We state that other responsibilities of teachers should be lessened and those responsible for teaching medical students should only be involved in their teaching role.

Before rounding practices it is highly important to have a plan for the round and preparation is vital. Instances such as simultaneous working round and teaching rounds $(17,23)$, difficulty in engaging all team members (4), and absence of team consistency (27) are main concerns in rounds. Also, our literature review expresses that teachers' lack of preparation $(4,19,23,26)$ jeopardize the integrity of their roles. Preparation helps teachers in better planning and conducting bedside encounter. By preparation, teachers can strengthen their clinical skills; improve their teaching skills, thus, augmenting their confidence at the bedside. This makes the bedside a thrilling venue for both the teacher and the learner (33). Medical students learn more in the clinical setting when clinical teachers are well prepared for their teaching roles. In this regard, organization and preparation could enhance the effectiveness of rounding practices for the benefit of medical teachers and medical students.

It is evident that medical teachers' good behaviors with patients play a part in assisting medical students learn humanistic aspects of care by observation. This underpins the use of role modeling when teaching in clinical rounds (34-37). Therefore, for every clinical encounter there must be the selection of positive role models to guarantee that teaching on rounds is delivered by excellent clinical teachers.

\section{Student-related factors (46 codes, 14.4\%)}

With regard to barriers with student factors, students' indiscipline and students' incompetency were the most frequently mentioned subcategories identified in our literature search. Non-compliance with time schedules (19) and dress code (23), disobeying professional disciplinary rules $(23,26)$ and unprofessional behavior (19) were mentioned among others regarding students' indiscipline.

Our findings also indicate that medical students' overall clinical skills and competencies are declining $(5,6,23)$. Although bedside teaching has long been considered the most effective method to teach clinical skills, but evidence shows that this form of teaching is progressively diminishing $(38,39)$, moving from patient's bedside to corridors and conference rooms, thus, students' lack of clinical skills or inadequate bedside teaching skills can be owing to the decreased frequency of clinical rounds at the bedside. This matter is so important that organizations such as the American Council for Graduate Medical Education (ACGME) and the WHO Advisory Committee on Medical training have recommended an increase for bedside teaching in their clinical curricula (40).

One of the most important areas of attention should be given to students' motivation. Evidence shows that motivation has an influence on learning, study behavior, academic success, and choice of specialty for medical students $(41,42)$. Our investigation revealed that lack of interest exists and medical students do not have the enthusiasm for learning $(6,14,19,23,25,26)$. This can have a significant effect on their future as a medical doctor concerning the required competency they need to acquire.

Other content areas identified in the literature that should be optimally addressed here include high work load $(4,5)$, poor participation $(21,26)$ and preparation $(21,23)$ as well as lack of courtesy to students $(6,25)$. These are vital aspects and their negligence in the way to prevent them can make learning on rounds too difficult for medical students.

\section{Patient-related factors ( 83 codes, 25.9\%)}

Our literature review showed that barriers concerning patient factors had the most frequency highlighting the sensitivity in the interpersonal aspects of teaching at the bedside on rounds. A clinical encounter can be poorly executed if patients feel uncomfortable being discussed by a large team (4), have concern for long stay of medical team by their bed (20), have multiple visits by medical students (23), and are burdened during bedside teaching (12). This kind of encounter disrespects patients and infringes their privacy. This concern has been refuted by the study which reported that patients actually enjoyed bedside teaching encounters (43). 
Prior studies have noted the instances of poor interpersonal communication $(5,6,23)$. If trust is not established between the patient and the medical team, real cooperation cannot be formed and the acquisition of clinical skills without patient involvement is not feasible. To avoid this pitfall, it is the job of medical teacher to set an amicable aura or atmosphere necessary during a clinical encounter. Medical teachers should bear in mind that the gathering of the clinical team at the patient bedside should be with courtesy and respect towards patients. As much of teaching and learning on rounds is through the discussion among the medical team, it may be fraught with medical terms or jargon $(4,23)$. This hinders communication with patient and causes patient to lose interest during the bedside round. In this case, the avoidance of medical jargon is recommended and lay terms should be substituted. Similarly, patients should be told that the theoretical discussions are primarily intended for teaching and may not be applicable to their illness.

Another striking finding is the selection of patients on rounding practices. Evidence shows that conditions such as medically unstable patients (4), patients being on contact or respiratory isolation $(6,44)$, patients very sick or not interested in participating (17), lack of suitable patients (16), etc. make teaching on rounds very daunting since at times these patients have unique medical conditions which are "must to learn" for medical students, but due to the conditions beyond the control of medical teachers they cannot be incorporated into the teaching.

Our literature review also revealed that the number of patients present on rounds can be a barrier; both the high volume $(6,24,25,27)$ and the low volume $(3,17,20)$ of patients. Although patient volume can be described as a barrier to teaching on rounds, we believe that it is contextbased and it is dependent upon which ward students are spending their rotation. In fact, core rotations such as surgery or internal medicine are usually abundant with many patients which make teaching daunting on rounds. In such a setting, medical teachers can be tempted to make perfunctory efforts to accommodate bedside rounds due to increased patient volume. Conversely, in minor rotations there is a dire need of patients with good clinical signs to present to medical students.

\section{Personnel-related factors (4 codes, $1.2 \%$ )}

Although we identified few codes concerning this factor in the literature, but the role of staff in clinical context is critically important. For instance, a study conducted by Poorghaneh and Hosseini showed that nursing staff play a pivotal role in helping students learn in the clinical context. Findings of this study revealed that $63.5 \%$ of nursing students believed that nursing staff had an essential role in clinical teaching and $60.6 \%$ provided an environment conducive to learning (45). Our literature review showed that rounding practices are undertaken without the support from ward staff (3), and staff is not interested in rounds (25) and at times in which access to nursing staff is necessary, they are not present on rounds (15). Therefore, it is important to inculcate in medical team, especially auxiliary staff, an attitude of cooperation and explicitly set rules for their presence in every clinical encounter. On the other hand, we should bear in mind that their clinical responsibilities are not affected by their presence at the patient bedside.

\section{Limitations}

This study has its own limitations. First, we restricted our search to English-language publications as it was not possible to include studies in other languages in our review. Second, it is unfortunate that the authors of this review decided to only include original papers not articles of other types or grey literature sources. Third, the major limitation of this study can be the subjective nature of data categorization, but authors of this investigation strived to reach consensus upon any category and the opinion of an external reviewer was sought.

The strengths of this study lie in the fact that we used an explicit and systematic search method with pre-specified eligibility criteria to collate as many papers as possible. Also, we explored the barriers stated from the main stake holders in rounding practices (i.e. medical teachers and medical students). The last but not least, in order to avert any errors, minimize potential biases as well as making sure that relevant studies are kept, two members of our research team independently did the study selection and data extraction. We also sought help from an external reviewer to cross- check our data.

\section{Conclusion}

Although clinical rounds are highly regarded, but the context of teaching and learning in rounds is ample with multiple variables which can make rounding practices an underutilized approach if no heed is given to the identified barriers embedded in the clinical context. By tackling the barriers in rounding practices, quality can be ensured. Evidence shows that quality is meeting the expectations of the consumer or satisfaction of clients (46). By the same token, teaching in this setting is so complicated and multidimensional $(47,48)$ which necessities meticulous exploration of the factors surrounding it.

Future researches can be tailored on identifying the barriers from the perspective of patients and personnel in the clinical context. In addition, the identified main categories with its subcategories can shed light on more researches to design studies to find remedies for the identified barriers and in making well-informed decisions concerning the rounding practices.

\section{Authors' Contributions}

All authors significantly contributed to this review paper in terms of its conception, design, analysis, data interpretation and are accountable for its content. The 
final draft of the paper was approved by all authors before publication.

\section{Ethical issues}

This article is part of a PhD. thesis conducted by Dr. Amin Beigzadeh at Isfahan University of Medical Sciences with code number 396165 .

\section{References}

1. Ramani S, Leinster S. AMEE Guide no. 34: teaching in the clinical environment. Med Teach 2008; 30(4): 347-64. doi: 10.1080/01421590802061613.

2. Spencer J. Learning and teaching in the clinical environment. BMJ 2003; 326(7389): 591-4. doi: 10.1136/ bmj.326.7389.591.

3. Nair BR, Coughlan JL, Hensley MJ. Impediments to bed-side teaching. Med Educ 1998; 32(2): 159-62. doi: 10.1046/j.1365-2923.1998.00185.x.

4. Ramani S, Orlander JD, Strunin L, Barber TW. Whither bedside teaching? a focus-group study of clinical teachers. Acad Med 2003; 78(4): 384-90. doi: 10.1097/00001888200304000-00014

5. Williams KN, Ramani S, Fraser B, Orlander JD. Improving bedside teaching: findings from a focus group study of learners. Acad Med 2008; 83(3): 257-64. doi: 10.1097/ ACM.0b013e3181637f3e.

6. Gonzalo JD, Heist BS, Duffy BL, Dyrbye L, Fagan MJ, Ferenchick G, et al. Identifying and overcoming the barriers to bedside rounds: a multicenter qualitative study. Acad Med 2014; 89(2): 326-34. doi: 10.1097/acm.0000000000000100.

7. Beigzadeh A, Yamani N, Bahaadinbeigy K, Adibi P. Challenges and problems of clinical medical education in Iran: a systematic review of the literature. Stride Dev Med Educ 2019; 16(1): e89897. doi: 10.5812/sdme.89897

8. Beigzadeh A, Adibi P, Bahaadinbeigy K, Yamani N. Strategies for teaching in clinical rounds: a systematic review of the literature. J Res Med Sci 2019; 24: 33. doi: 10.4103/jrms.JRMS_460_18.

9. Cole FL. Content analysis: process and application. Clin Nurse Spec 1988; 2(1): 53-7. doi: 10.1097/00002800198800210-00025.

10. Cavanagh S. Content analysis: concepts, methods and applications. Nurse Res 1997; 4(3): 5-16. doi: 10.7748/ nr.4.3.5.s2.

11. Hsieh HF, Shannon SE. Three approaches to qualitative content analysis. Qual Health Res 2005; 15(9): 1277-88. doi: $10.1177 / 1049732305276687$.

12. Jones P, Rai BP. The status of bedside teaching in the United Kingdom: the student perspective. Adv Med Educ Pract 2015; 6: 421-9. doi: 10.2147/amep.s83407.

13. Indraratna PL, Greenup LC, Yang TX. Bedside teaching in Australian clinical schools: a national study. Journal of Biomedical Education 2013; 2013: 948651. doi: 10.1155/2013/948651.

14. Force J, Thomas I, Buckley F. Reviving post-take surgical ward round teaching. Clin Teach 2014; 11(2): 109-15. doi: 10.1111/tct.12071.

15. Gonzalo JD, Masters PA, Simons RJ, Chuang CH. Attending rounds and bedside case presentations: medical student and medicine resident experiences and attitudes. Teach Learn
Med 2009; 21(2): 105-10. doi: 10.1080/10401330902791156.

16. Celenza A, Rogers IR. Qualitative evaluation of a formal bedside clinical teaching programme in an emergency department. Emerg Med J 2006; 23(10): 769-73. doi: 10.1136/emj.2006.037796.

17. Shehab A. Clinical teachers' opinions about bedside-based clinical teaching. Sultan Qaboos Univ Med J 2013; 13(1): 121-6. doi: 10.12816/0003205.

18. Holla R, Shrisha M, Unnikrishnan B, Sharma N, Janani $\mathrm{S}$, Thapar R, et al. Facilitators and barriers for bedside teaching in the teaching hospitals of coastal south India. Asian J Pharm Clin Res 2015; 8(2): 271-3.

19. Dybowski C, Harendza S. Bedside teaching: general and discipline-specific teacher characteristics, criteria for patient selection and difficulties. GMS Z Med Ausbild 2013; 30(2): Doc23. doi: 10.3205/zma000866.

20. Al-Swailmi FK, Khan IA, Mehmood Y, Al-Enazi SA, Alrowaili M, Al-Enazi MM. Students' perspective of bedside teaching: a qualitative study. Pak J Med Sci 2016; 32(2): 351-5. doi: 10.12669/pjms.322.9194.

21. Dewhurst G. Time for change: teaching and learning on busy post-take ward rounds. Clin Med (Lond) 2010; 10(3): 231-4. doi: 10.7861/clinmedicine.10-3-231.

22. Janicik RW, Fletcher KE. Teaching at the bedside: a new model. Med Teach 2003; 25(2): 127-30. doi: 10.1080/0142159031000092490.

23. Soltani Arabshahi K, Haghani F, Bigdeli S, Omid A, Adibi P. Challenges of the ward round teaching based on the experiences of medical clinical teachers. J Res Med Sci 2015; 20(3): 273-80.

24. Jaye C, Egan T, Smith-Han K, Thompson-Fawcett M. Teaching and learning in the hospital ward. $\mathrm{N} \mathrm{Z} \mathrm{Med} \mathrm{J}$ 2009; 122(1304): 13-22.

25. Castiglioni A, Shewchuk RM, Willett LL, Heudebert GR, Centor RM. A pilot study using nominal group technique to assess residents' perceptions of successful attending rounds. J Gen Intern Med 2008; 23(7): 1060-5. doi: 10.1007/ s11606-008-0668-z.

26. Khan IA. Bedside teaching-making it an effective instructional tool. J Ayub Med Coll Abbottabad 2014; 26(3): 286-9.

27. Claridge A. What is the educational value of ward rounds? a learner and teacher perspective. Clin Med (Lond) 2011; 11(6): 558-62. doi: 10.7861/clinmedicine.11-6-558.

28. Najafi N, Monash B, Mourad M, Ding Y, Glass M, Burrell GJ, et al. Improving attending rounds: qualitative reflections from multidisciplinary providers. Hosp Pract (1995) 2015; 43(3): 186-90. doi: 10.1080/21548331.2015.1043181.

29. O'Daniel M, Rosenstein AH. Professional communication and team collaboration. In: Hughes RG, ed. Patient Safety and Quality: An Evidence-Based Handbook for Nurses. Rockville, MD: Agency for Healthcare Research and Quality (US); 2008.

30. Joint Commission Resources. The Joint Commission Guide to Improving Staff Communication. Oakbrook Terrace, IL: Joint Commission Resources; 2005.

31. Montazeri H, Beigzadeh A, Shokoohi M, Bazrafshan A, Esmaili M. Perceptions of students and clinical instructors of academic learning environments at Yazd University of Medical Sciences. Res Dev Med Educ 2012; 1(2): 65-70. doi: 10.5681/rdme.2012.014. 
32. Beigzadeh A, Bahaadinbeigy K, Adibi P, Yamani N. Identifying the challenges to good clinical rounds: a focusgroup study of medical teachers. J Adv Med Educ Prof 2019; 7(2): 62-73. doi: 10.30476/jamp.2019.44710.

33. Cox K. Planning bedside teaching--1. Overview. Med J Aust 1993; 158(4): 280-2.

34. Bahmanbijari B, Beigzadeh A, Etminan A, Rahmati Najarkolai A, Khodaei M, Seyed Askari SM. The perspective of medical students regarding the roles and characteristics of a clinical role model. Electron Physician 2017; 9(4): 4124-30. doi: 10.19082/4124.

35. Bahman Bijari B, Zare M, Haghdoost AA, Bazrafshan A, Beigzadeh A, Esmaili M. Factors associated with students' perceptions of role modelling. Int J Med Educ 2016; 7: 3339. doi: 10.5116/ijme.57eb.cca2.

36. Beigzadeh A, Rahimi M, Lashkari M, Haghdoost A, Seyed Askari SM. A survey on the characteristics of an effective clinical teacher from the viewpoints of nursing students at Kerman University of Medical Sciences. Iran Journal of Nursing 2015; 28(95): 44-53. doi: 10.29252/ijn.28.95.44.

37. Esmaeili M, Haghdoost AA, Beigzadeh A, Bahman Bijari B, Bazrafshan A. Personal and scientific characteristics of positive and negative role models among medical educators from the viewpoint of dentistry and pharmacy students in Kerman University of Medical Sciences. Stride Dev Med Educ 2013; 10(3): 298-311. [[In Persian]].

38. Ende J. What if Osler were one of us? Inpatient teaching today. J Gen Intern Med 1997; 12(Suppl 2): S41-8. doi: 10.1046/j.1525-1497.12.s2.6.x.

39. LaCombe MA. On bedside teaching. Ann Intern Med 1997; 126(3): 217-20. doi: 10.7326/0003-4819-126-3-19970201000007.

40. RamaniS.Twelvetipstoimprovebedsideteaching. MedTeach
2003; 25(2): 112-5. doi: 10.1080/0142159031000092463.

41. Kusurkar RA, Ten Cate TJ, van Asperen M, Croiset G. Motivation as an independent and a dependent variable in medical education: a review of the literature. Med Teach 2011; 33(5): e242-62. doi: 10.3109/0142159x.2011.558539.

42. Bahmanbijar B, Nazarieh M, Toufan N, Dehghani MR, Beigzadeh A. Identification of the reasons behind students' lack of participation in classroom activities using a Delphi technique. Future of Medical Education Journal 2019; 9(2): 10-7. doi: 10.22038/fmej.2019.15154.1091.

43. Wang-Cheng RM, Barnas GP, Sigmann P, Riendl PA, Young MJ. Bedside case presentations. J Gen Intern Med 1989; 4(4): 284-7. doi: 10.1007/bf02597397.

44. Gonzalo JD, Heist BS, Duffy BL, Dyrbye L, Fagan MJ, Ferenchick G, et al. The art of bedside rounds: a multicenter qualitative study of strategies used by experienced bedside teachers. J Gen Intern Med 2013; 28(3): 412-20. doi: 10.1007/s11606-012-2259-2.

45. Poorghaneh P, Hosseini MA. The role of nursing staff in nursing students' learning in clinical settings. J Med Educ Dev 2010; 3(4): 7-11. [[In Persian]].

46. Yousefy A, Changiz T, Yamani N, Zahrai RH, Ehsanpour S. Developing a holistic accreditation system for medical universities of the Islamic Republic of Iran. East Mediterr Health J 2009; 15(3): 747-56.

47. Parsell G, Bligh J. Recent perspectives on clinical teaching. Med Educ 2001; 35(4): 409-14. doi: 10.1046/j.13652923.2001.00900.x.

48. Yamani N, Moosavi SA, Alizadeh M, Khorvash F, Ghiasi M. A 360-degree performance evaluation of emergency medicine ward in Alzahra hospital. J Pak Med Assoc 2012; 62(3 Suppl 2): S13-7. 